\title{
A RARE CASE OF SMALL CELL LUNG CANCER WITH SKIN METASTASES
}

\author{
Preetam R. Acharya1, Tanuj Kanchan², Santosh Rai ${ }^{3}$
}

\section{HOW TO CITE THIS ARTICLE:}

Preetam R. Acharya, Tanuj Kanchan, Santosh Rai. "A Rare Case of Small Cell Lung Cancer with Skin Metastases". Journal of Evolution of Medical and Dental Sciences 2015; Vol. 4, Issue 40, May 18; Page: 7079-7082,

DOI: $10.14260 /$ jemds/2015/1029

ABSTRACT: SUMMARY: A 75 year old male admitted with confusion was diagnosed to have small cell cancer in the right lower lobe of lung. On detailed evaluation he was also found to have a metastatic malignant ulcer over his left inguinal region. The rarity of skin metastases in lung cancer, the infrequent propensity of small cell cancer to metastasize to the skin, the ulcerative nature of skin metastasis and its location far off from the primary in the lung prompted us to report this case.

KEYWORDS: cutaneous metastases, malignant ulcer, small cell lung cancer.

INTRODUCTION: Lung cancer is the most common cancer worldwide. The International Agency for Research on Cancer in its GLOBOCON Project estimated that in 2008, with 1.61 million new cases (12.7\% of all new cancers) lung cancer was the most common cancer in both the sexes. It was also the most common cause of death from cancer with 1.38 million deaths (18.2\% of total deaths).[1] Lung cancer can metastasize to almost every organ the frequent metastatic sites being the liver, adrenal, brain, bone and kidneys. Although considered highly metastatic, small cell cancers of the lung are rarely associated with skin secondaries - a fact which prompted us to report this case.

CASE REPORT: A 75 year old hypertensive, non-diabetic man was admitted with a short history of disorientation, delusion and hallucinations. He had cough with mucopurulent sputum since 2 months and anorexia leading to the loss of about $4 \mathrm{~kg}$ weight in 2 months. He had no fever, chest pains, hemoptysis or breathing difficulty. Patient was an ex-smoker who smoked about half a packet of beedi (Indian hand rolled cigarette)/ day for 30 years and a cook by profession. He had taken a course of anti-TB drugs for pulmonary TB 8 years back. He was hospitalized for right middle lobe pneumonia 2 years back during which the sputum tests for AFB were negative. On examination, he was disoriented but responded to verbal commands; there were no focal neurological deficits/signs.

Rest of the neurological examination was normal. Respiratory system examination revealed reduction in the breath sounds over the right infrascapular and infraaxillary areas. Patient was treated with intravenous $0.9 \%$ saline and antibiotics (i.v. co-amoxyclav with p.o. clarithromycin). Patient's sensorium improved with the correction of his hyponatremia. On the day of discharge relatives complained that the patient had of late developed a habit of scratching his left groin. On interrogation, the patient admitted that he had hidden the fact that he had developed a small lump over his left groin which had burst to release pus causing him local irritation. Local examination showed an ulcer of size $4 \mathrm{~cm} \mathrm{X} 4 \mathrm{~cm}$ with raised floor, base covered with dirty slough, indurated edges and a palpable left inguinal lymph node.

INVESTIGATIONS: Blood investigations showed elevation in ESR $57 \mathrm{~mm} / 1^{\text {st }}$ hour and hyponatremia (serum Na+: $125 \mathrm{mEq} / \mathrm{L}$ ). Serum osmolality was mildly increased (patient value: $287 \mathrm{~m} \mathrm{osm} / \mathrm{kg}$, normal: 270-285 m osm/kg), urine osmolality was normal (patient value: $177 \mathrm{~m}$ osm $/ \mathrm{kg}$, normal: 50 - 
$1400 \mathrm{~m} \mathrm{osm} / \mathrm{kg}$ ) and urinary sodium was normal (patient value $32 \mathrm{mmol} / \mathrm{L}$ ). CT study of his brain was unremarkable. Chest radiograph showed a homogenous opacity occupying the right mid and lower zone of the lung with silhouette of the right diaphragm (Figure 1). Sputum for AFB stain was negative and the culture grew oropharyngeal flora. Contrast enhanced CT chest showed an enhancing soft tissue mass with irregular margins and central necrosis, measuring $8 \mathrm{~cm} \mathrm{X} 4.4 \mathrm{~cm}$ in the right lower lobe of the lung abutting the pleura with enlarged mediastinal lymph nodes in the azygoesophageal recess (Figure 2). A CT guided FNAC from the lung mass suggested malignancy and biopsy report showed the histopathology to be small cell carcinoma. Ulcer edge biopsy and FNAC of lymph node was done the report of which came as metastatic small cell carcinoma.

DIFFERENTIAL DIAGNOSIS: The final diagnosis was small cell carcinoma of the lung (Extensive stage) with cutaneous metastases (Malignant skin ulcer) based on the above mentioned investigations.

Differential diagnosis in this case includes the possibility of the lung mass being a metastases from a primary neuroendocrine carcinoma of the skin (Merkel cell carcinoma, primary small cell carcinoma of the skin) - an uncommon but aggressive skin tumor with a propensity to metastasize to the lung. Complex immunohistochemical tests can help differentiate in between the two entities.[2]

The poor survival rates in both - small cell carcinoma of lung and a 'merkeloma' with distant metastases deferred us from pursuing with further detailed immunohistochemical studies in this patient.

OUTCOME AND FOLLOW-UP: Opinion was taken from the oncologist and palliative chemotherapy was advised keeping in mind patient age, general fitness level and the advanced stage, which the patient refused. A few days later the patient died peacefully at home.

DISCUSSION: Skin involvement in lung cancer may be either by direct extension to the chest wall and skin or present as a metastatic cutaneous nodule. In addition, a variety of paraneoplastic phenomena involving the skin has been described.[3] With the exception of malignant melanoma, lung and breast cancers, visceral malignancies rarely metastasize to the skin. In case of lung cancer, the reported rate of skin secondaries varies from $0.5 \%$ to $9 \% .{ }^{[4]}$ A large meta-analysis reported the incidence to be $5.3 \%{ }^{[5]}$ The detection of skin metastases in lung cancer signifies end-stage disease and confers a poor prognosis.[3]

The tumor cells find their way to the skin by the hematogenous or lymphatic route. One suggested hypothesis is an exfoliation from the lung primary, intravasation into the circulation, stasis in a blood vessel followed by the extravasation and invasion into the recipient tissue bed and subsequent proliferation into a tumorlet.[6]

Cutaneous metastases may present as a late event in a patient with known malignancy (As in our case) or may be the presenting feature of an occult malignancy or may be the first sign of recurrence in a tumor thought to be in remission.[7] Skin metastases are usually single and are located in proximity to the primary malignancy. An Indian series reported the commonest sites to be the scalp, head, neck (49\%), trunk (37\%) followed by lower limb (5\%) and upper limb (2\%) ${ }^{[3]}$. A study by Zaky et al showed the chest, abdomen and scalp to be the common sites.[8] However, in our patient the metastatic malignant ulcer was located well away, and on the side contralateral to the primary within the lung. 
The most common pathological type of lung cancer to have skin metastases is adenocarcinoma and small cell lung cancers (Otherwise well known for early aggressive metastatic behavior) are the least likely to have a skin secondary.[3,6] Patients with skin metastases from a lung neoplasm generally have metastatic lesions in other organs as well.[9] In our patient, the histopathology of lung primary was small cell carcinoma and no other organ metastasis was identified on routine evaluation.

Skin metastases have varied physical appearances well described in previous literature. Skin ulcers or ulcerated nodules (As in our patient) are relatively uncommon. In conclusion, since skin metastases lack one single pathognomic physical appearance, the treating physician should have a high index of suspicion and call for an early biopsy of all such lesions.

\section{LEARNING POINTS:}

- Skin metastases though rare should be considered in the differential diagnosis of skin lesions in patients with lung cancer.

- Since cutaneous metastases lack one pathognomic physical appearance they need to be biopsied regardless of their appearance and location.

\section{REFERENCES:}

1. Ferlay J, Shin HR, Bray F, Forman D, Mathers C and Parkin DM. GLOBOCAN 2008 v2.0, Cancer Incidence and Mortality Worldwide: IARC Cancer Base No. 10 [Internet]. Lyon, France: International Agency for Research on Cancer; 2010. Available from: http://globocan.iarc.fr.

2. Smith PD, Patterson JW. Merkel Cell Carcinoma (Neuroendocrine Carcinoma of the Skin). Am J Clin Pathol 2001; 115(Suppl 1): S68-S78.

3. Kamble R, Kumar L, Kochupillai V et.al. Cutaneous metastases of lung cancer. Postgrad Med J 1995; 71: 741-743.

4. Giovagnorio F, Valentini C, Paonessa A. High Resolution and Color Doppler Sonography in the Evaluation of Skin Metastases. J Ultrasound Medicine 2003; 22: 1017-1022.

5. Krathen RA, Orengo IF, Rosen T. Cutaneous metastases: a meta-analysis of data. South Med J 2003; 96(2): 164-7.

6. Simsek GG, Karadag AS, Turksen Z. Cutaneous metastases of the small cell lung cancer. Indian J Dermatol Venereol Leprol 2011; 77: 537.

7. Wollina U, Graefe T, Konrad H, Schonlebe J et al. Cutaneous metastases of internal cancer. Acta Dermatoven APA 2004; 13(3): 79-84.

8. Zaky AH, Abd El-Wanis ME, Hamza H, Abdel-Hafez HZ, Abdel-Azim NE. Cutaneous Metastases from Different Internal Malignancies in Egypt. Middle East Journal of Cancer 2010; 1(3): 135139.

9. Coslett ML, Katlic MR. Lung Cancer with Skin Metastasis. Chest 1990; 97: 757-59. 


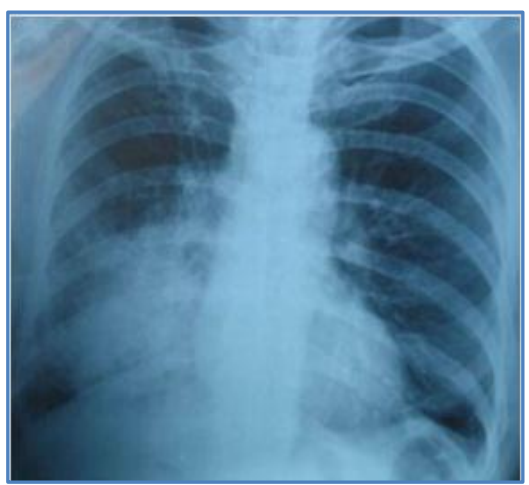

Fig. 1: Chest Radiograph (PA view) showing right mid-zone and lower-zone opacity

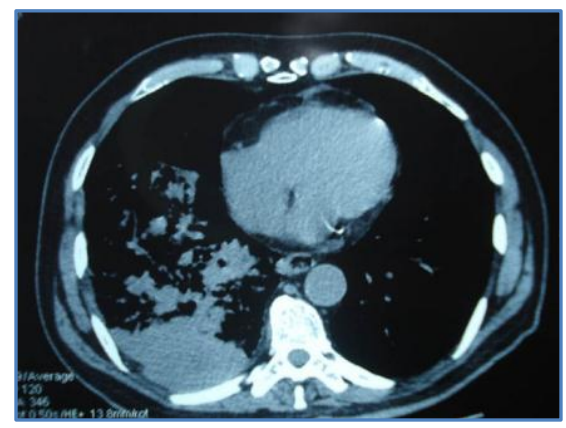

\section{Fig. 2: CT scan of Chest showing soft tissue mass with} irregular margin in the right lower lobe of lung

\section{AUTHORS:}

1. Preetam R. Acharya

2. Tanuj Kanchan

3. Santosh Rai

\section{PARTICULARS OF CONTRIBUTORS:}

1. Associate Professor, Department of Pulmonary Medicine, Kasturba Medical College, Manipal University, Manipal, Mangalore, Karnataka.

2. Associate Professor, Department of Forensic Medicine \& Toxicology, Kasturba Medical College, Manipal University, Manipal, Mangalore, Karnataka.

\section{FINANCIAL OR OTHER} COMPETING INTERESTS: None
3. Associate Professor, Department of Radiodiagnosis, Kasturba Medical College, Manipal University, Manipal, Mangalore, Karnataka.

\section{NAME ADDRESS EMAIL ID OF THE} CORRESPONDING AUTHOR:

Dr. Preetam R. Acharya,

B-7, KMC Staff Quarters, Light House Hill Road, Hampankatta, Mangalore-575001, Karnataka.

E-mail: dokpreet@yahoo.co.in

Date of Submission: 23/04/2015.

Date of Peer Review: 25/04/2015.

Date of Acceptance: 08/05/2015.

Date of Publishing: 18/05/2015. 